\title{
Design and Selection of the Braking System for All Terrain Vehicle
}

\author{
Prof. L. B. Diwakar ${ }^{1}$ \\ Automobile Engineering, \\ S.E.S. Polytechnic Solapur. \\ Maharashtra, India,
}

\author{
S. L. Diwakar ${ }^{2}$ \\ Mechanical Engineering \\ Dr. D. Y. Patil institute of Technology, Pimpri, \\ Pune, Maharashtra, India
}

\author{
V.V. Deshpande ${ }^{3}$ \\ Mechanical Engineering \\ Dr. D. Y. Patil Institute of Technology, Pimpri. Pune, \\ Maharashtra, India
}

\begin{abstract}
In this paper the basic brake function and elements of brake Systems are discussed. Operator pedal effort Limits and braking Performance are reviewed. Brake design and product development guides are introduced along with design selection procedure. Also the following paper is presented with a specific objective to design a hydraulic brake system for All Terrain Racing Vehicle. The ultimate objective of the braking system is to lock all four wheels of the vehicle at the same instant and stop its motion within minimum stopping distance. The outcome of this project is an optimized hydraulic brake system being light in weight providing adequate braking torque for efficient braking of the vehicle in hostile racing environment. Hydraulic Disc Braking system is most suitable for such hostile racing conditions.
\end{abstract}

\section{Keywords- Hydraulic Disc Brake, All terrain racing vehicle}

\section{INTRODUCTION}

The basic function of a brake system are to slow down the speed of the vehicle. To maintain its speed during down hill operation, and to hold the vehicle stationary after it has come to a complete stop. These basic functions have to be performed during normal operation of the Brakes. And to a lesser degree of braking effectiveness during a brake system failure.

All brake systems can be divided into four basic subsystems like:

1. Energy source: This includes the components of a brake system that produce, store, And make available the energy required for braking. The energy source subsystem ends where driver controlled modulation of the energy supply begins. The fundamental component for that category is the master cylinder.

2. Apply system: This includes all components that are used to modulate the level of braking. The apply subsystem ends where the energy required for applying the brakes enters the energy transmission system. More Specifically Pedals and the leverage parts are includes.

3. Energy transmission system: This includes all components through which the energy required for applying the brakes travels from the apply system to the wheel brakes. Brake rubes required for carrying hydraulic or air medium are part of the energy transmission system. Metallic rigid brake tubes commonly are called brake fines, whereas flexible tubes are called brake hoses.

4. Actuation System: These are the components where the forces are produced which oppose the existing or intended vehicle motion. mostly this system includes the calipers wheel cylinders, disc rotors

A typical hydraulic brake system is illustrated in Figure 1. It covers all the fundamental parts of the hydraulic break system.

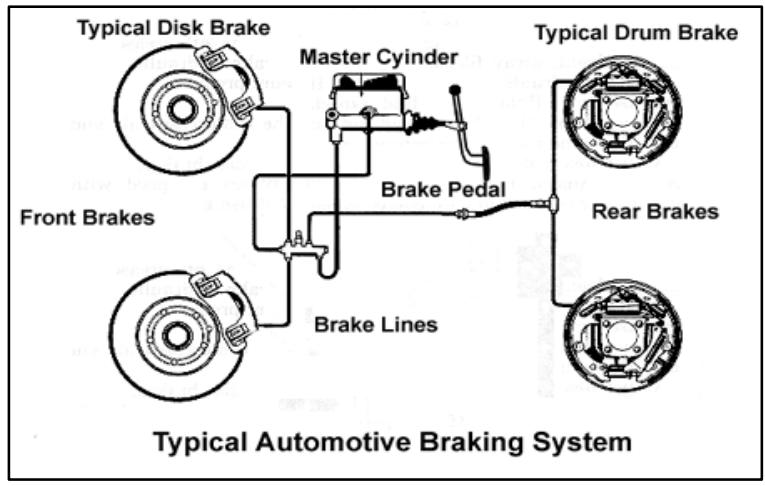

Figure 01A

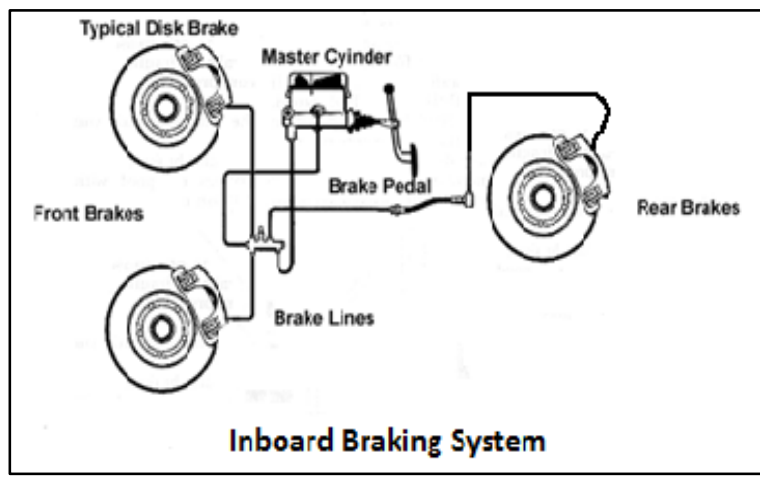

Figure 01B

Figure 1 A illustrate the basic structure of the braking systems of the commercial vehicle and then Figure 1B illustrate the special peruse inboard braking system. Today it is more popular in BAJA ATV's. 


\section{DESIGN OF THE BRAKE SYSTEM FOR BAJA ATV:}

For the brake system of the off-road vehicle more specifically for the SAE BAJA Dune buggy all the four wheels should be lock at same time. Now a day's inboard braking system is more popular in the BAJA vehicles. In board means the only single disc and caliper set is used for the locking the rear wheels.

So the design calculation of the braking system is begins with the dynamic load transfer on the axels. This load transfer has to be calculated because its gives the value of required braking torque on the wheels.

\section{A. Dynamic Load transfer:}

Basically it is the calculation of the reaction forces act on the front and rear axles due to self-weight

In the inboard system a single rotor and the caliper is used for locking the both rear wheels. This system is used only for that vehicle which doesn't have rear differential unite.

Load distribution between front axle and rear axle

Basically it is the calculation of the reaction forces act on the front and rear axles due to self-weight transfer of the vehicle while deceleration generated to stop the vehicle. Figure 02 illustrate the location of the $\mathrm{CG}$ in the vehicle chassis and some another parameters.

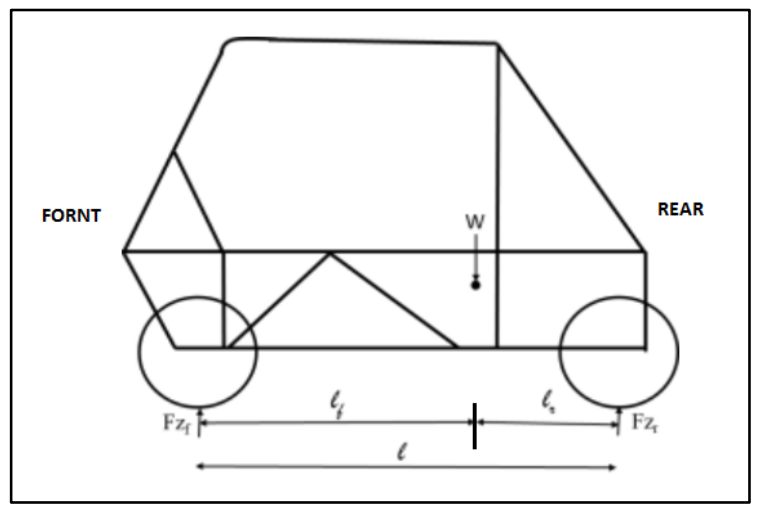

Figure 02

$\Psi=$ Static C Transfer

Mf dyn $=$ Mass on Front axle $=\frac{1477.14}{9.81}=149.66 \mathrm{Kg}$

$\mathrm{M}=$ Mass of Vehicle $=207.26 \mathrm{Kg}$

$\mathrm{X}=$ Relative $\mathrm{C} . \mathrm{G}=\frac{h}{b}=\frac{0.5529}{1.27}=0.4353$

$\mathrm{a}=$ Deceleration in $\mathrm{g}$ units $=\frac{6.67}{9.81}=0.68 \mathrm{~g}$

So,

$1-\Psi=\frac{144.66}{207.26}-(0.4353 \times 0.68)$

$1-\Psi=0.4336$

$\Psi=0.5664$
$\mathrm{Rf}=\frac{W(x+\mu h) \cos \theta}{b}$

$\operatorname{Rr}=\frac{W(b-x-\mu h) \cos \theta}{b}$

Where,

$\mathrm{Rf}=$ Load on front axle,

$\mathrm{Rr}=\mathrm{Load}$ on rear axle,

$\mathrm{x}=$ Distance of C.G from rear axle $=21.683 \mathrm{in}=0.5507 \mathrm{~m}$

$\mathrm{b}=$ Wheel Base $=50$ in $=1.27 \mathrm{~m}$

$\mathrm{h}=$ Height of C.G from Ground $=21.27$ in $=0.5529 \mathrm{~m}$

$\mu=$ Coefficient of friction between tyre and road $=0.68$ (it is the value for the gravel road)

$\mathrm{W}=\mathrm{Weight}$ of Vehicle $=207 \times 9.81=2060.63 \mathrm{~N}$

$\Theta=$ Angle between horizontal and inclined plane $=0$

Now,

$$
\begin{aligned}
\mathrm{Rf} & =\frac{2060.63(0.5507+0.68 \times 0.5529) \cos 0}{1.27} \\
& =1477.455 \mathrm{~N}
\end{aligned}
$$

$\operatorname{Rr}=\frac{2060.63(1.27-0.5507-0.68 \times 0.5529) \cos 0}{1.27}$

$$
=584.78 \mathrm{~N}
$$

Now,

$$
\begin{aligned}
& W \sin \theta+\frac{W}{g} \alpha=\mu(\mathrm{Rf}+\mathrm{Rr}) \\
& 2060.63(0)+\frac{2060.63}{9.81} \alpha=0.68(1477.4+584.78) \\
& \alpha=6.67 \mathrm{~m} / \mathrm{s}^{2} \text { (deceleration) } \\
& {[(1-\Psi)+(\text { X.a) }] \mathrm{M}=\text { Mf dyn }}
\end{aligned}
$$

Where,

Now,

$$
\begin{aligned}
\mathrm{Mr} & =\Psi \mathrm{M} \\
& =0.5664 \times 207.26 \\
& =110.419 \mathrm{Kg}
\end{aligned}
$$

The load transfer result is

In Dynamic Condition

Load on Front Side $=72.96 \%$

Load on Rear Side $=27.03 \%$

In Static Condition,

Load on Front Side $=43.36 \%$ 
Load on Rear Side $=56.64 \%$

Now getting the values of the dynamic load transfer on the axel we can calculate the required braking force and braking torque.

\section{B. Required Braking Forces and Torque:}

$\mathrm{FB}=$ M.a.g

Where,

$\mathrm{M}=$ Mass of Vehicle $=207.26 \mathrm{Kg}$

$\mathrm{a}=$ Deceleration in $\mathrm{g}$ units $=0.68 \mathrm{~g}$

$\mathrm{g}=$ Acceleration due to Gravity $=9.81$

$\mathrm{FB}=207.26 \times 0.68 \times 9.81$

$=1322.15 \mathrm{~N}$

Now,

In Dynamic Conditions,

For Front Side,

$\mathrm{FBF}=\mu \times \mathrm{Rf}$

$=0.68 \times 1477.4$

$=965.01 \mathrm{~N}$

$\mathrm{z}=\mathrm{FBF} \times \mathrm{RWheel}$

$($ RWheel $=11.5 \mathrm{in}=0.2921 \mathrm{~m})$

$=965.01 \times 0.2921$

$=281.87 \mathrm{~N} . \mathrm{m}$

Torque on Single Wheel,

$\mathrm{z}=281.87 / 2$

$=140.93 \mathrm{~N} \cdot \mathrm{m}$

For Rear Side,

$\mathrm{FBF}=\mu \times \mathrm{Rr}$

$=0.68 \times 584.78$

$=357.53 \mathrm{~N}$

$\mathrm{z}=\mathrm{FBF} \times \mathrm{RWheel}$

( RWheel $=11.5$ in $=0.2921 \mathrm{~m}$ )

$=357.53 \times 0.2921$

$=104.43$ N.m

C. Design of the system for required:

Now we get the required values to stop the vehicle. So we have to design the braking system to generate this required parameters.
Here the first thing comes that is pedal assembly. This assembly is come in the direct contact of the driver. Driver can varies the pressure to adjust the brake power. Pedal travel and the driver's effort affect the brake power. There is some popular pedal assembly used for Baja ATV s illustrated in the Figure 03. Mostly the first type is used to utilize the minimum space

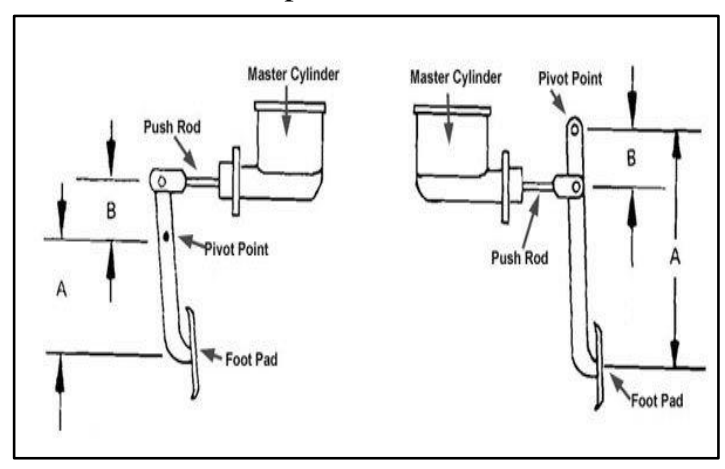

Figure 03A.

The system should be worked on minimum driver's effort so 7:1 pedal ratio is selected. I.e. $\mathrm{B}$ is 1 and $\mathrm{A}$ is 7 .

Now,

Pedal Force $=300 \mathrm{~N}$

Bore Diameter of TMC $=19.05 \mathrm{~mm}$

Force act on $\mathrm{TMC}=\mathrm{FTMC}=7$ times Pedal Force

$$
\begin{aligned}
& =7 \times 300 \\
& =2100 \mathrm{~N}
\end{aligned}
$$

Area of TMC

$$
\begin{aligned}
=\mathrm{ATMC} & =\frac{\pi D^{2}}{4} \\
& =\frac{3.14 \times 0.01905^{2}}{4} \\
& =285.9 \times 10^{-6} \mathrm{~m} 2
\end{aligned}
$$

Pressure in $\mathrm{TMC}=\mathrm{PTMC}=\frac{F_{T M C}}{A_{T M C}}$

$$
=\frac{2100}{285.9 \times 10^{-6}}
$$

$=7.3245 \times \mathbf{1 0}^{\mathbf{6}} \mathrm{N} / \mathrm{m} 2$

$=73.245 \mathrm{Bar}$

Now,

Diameter of Piston of Front Caliper $=34 \mathrm{~mm}$

Diameter of Piston of Rear Caliper $=32 \mathrm{~mm}$

So,

Area of Front Caliper Piston $=\frac{\pi D^{2}}{4}$

$$
=\frac{3.14 \times 0.034^{2}}{4}
$$




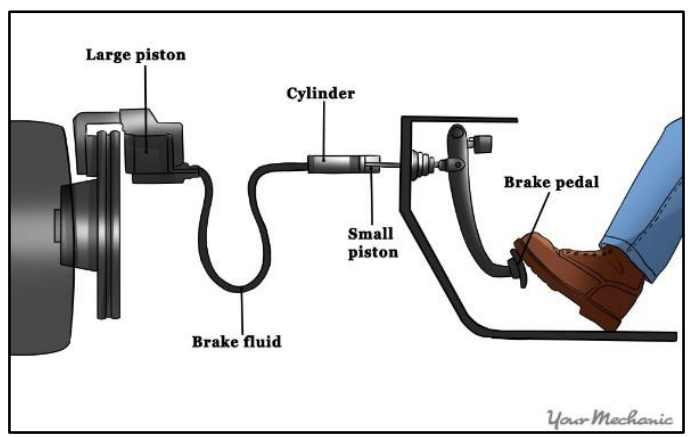

Figure 03B

$=9.0792 \times 10^{-4} \mathrm{~m} 2$

Area of Rear Caliper Piston $=\frac{\pi D^{2}}{4}$

$$
\begin{gathered}
=\frac{3.14 \times 0.032^{2}}{4} \\
=8.042 \times 10-4 \mathrm{~m} 2
\end{gathered}
$$

Now,

Force acting on Caliper,

So,

Clamping Force generated by front caliper,

$$
\begin{aligned}
F_{C P} & =\mu \times P_{T M C} \times \text { Area of Caliper } \\
& =0.34 \times 73.24 \times 9.0792 \times 10 \\
& =2267.038 \mathrm{~N}
\end{aligned}
$$

Generated Torque on single Wheel,

$$
\mathrm{z}=0.065 \times 2267.038
$$

( $0.065 \mathrm{~m}$ is the radius of the front disc rotors)

$$
=147.35 \mathrm{Nm}
$$

Clamping Force generated by rear Caliper,

$$
\boldsymbol{F}_{\boldsymbol{C P}}=2 \mu \times P_{T M C} \times \text { Area of Caliper }
$$

$$
\begin{aligned}
& =2 \times 0.34 \times 73.24 \times 8.042 \times 10 \\
& =4016.34 \mathrm{~N}
\end{aligned}
$$

Torque on Single Wheel,

$$
\mathrm{z}=2008.17 \times 0.070
$$

( $0.070 \mathrm{~m}$ is the radius of the rear disc rotors)

$$
=140.5719 \mathrm{Nm}
$$

Hence the conclusion is the system which we have selected is generate sufficient braking torque to stop the vehicle in minimum possible distance.

\section{CONCLUSION}

This system includes, $19.05 \mathrm{~mm}$ bore diameter $\mathrm{BOSSCH}$ TMC as energy source which consumes DOT3 brake fluid. A pedal as apply system with 7:1 pedal ratio center pivot system. Energy transmission system comprises of steel braided Teflon brake line. Which delivers the pressurized brake fluid to the actuation system. This actuation system includes two floating calipers at front with $34 \mathrm{~mm}$ bore diameter combination with the $170 \mathrm{~mm}$ diameter steel disc rotors. And at rear inboard actuation system includes the single fix type caliper of $32 \mathrm{~mm}$ bore diameter with $160 \mathrm{~mm}$ diameter steel disc rotor.

With the combination of this subassembly all wheels are locked at same time. Also the vehicle is stop with in the minimum stopping distance.

\section{REFRENCE}

[1] Limpert Rudolf "Brake design and Safety", Society of Automotive Engineers, Warrandable, Inc, PA, USA, 1992

[2] William D. Callister and Jr. David G. Rethwisch "Material science and engineering", Eighth Edition

[3] "The physics of braking system" Stop Tech: Hign performance braking system by Walker James (2005)

[4] "Engineering Design Handbook Analysis and Design of Automtive Brake systems by Darcom Pamphlet (1976)

[5] "Design of Machine Element Third Edition by V. B. Bhandari

[6] A companion to the "ASME Y14.5-2009" GD\&T Standard by Alex Krulikowski 